\title{
A Study on Foreign Teachers' English Teaching in Higher Vocational Colleges from the Perspective of World English
}

\author{
Muying Lin* \\ Zhejiang Tongji Vocational College of Science and Technology, Hangzhou 311231, Zhejiang Province, China \\ *Corresponding author: Muying Lin, oxygen0312@163.com
}

\begin{abstract}
There is a growing demand for foreign language teaching resources by higher vocational colleges. However, there are only a number of studies on the development and changes of English internationalization and its impact on foreign teachers' teaching in higher vocational colleges. This paper analyzes the current situation and concludes that for "good" international language education, EIL and WE should be integrated, and different cultures in curriculum design, teaching methods, class management, and evaluation system should be respected. Foreign teachers in higher vocational colleges have the obligation to deeply understand the explicit and implicit explicit forms and functions of language as well as implement them in the teaching process, so as to effectively identify the cultural identity of students, which is reflected in the second language learning process.
\end{abstract}

Keywords: Foreign teachers; English teaching; Higher vocational colleges; World English

Publication date: December 2021; Online publication: January 24, 2022

\section{Introduction}

With the advancement of globalization, higher vocational colleges are actively exploring strategies for cultivating students' English skills in the game of diversification and localization, so as to meet the increasingly urgent demand of the labor market for new applied language talents. Therefore, higher vocational colleges have a growing demand for foreign language teaching resources. Many higher vocational colleges have hired foreign teachers to engage in English teaching. However, there are only several studies on the development and changes in the internationalization of English and its impact on foreign teachers' teaching in higher vocational colleges. In addition, the complexity of language skills and many other factors also put forward higher requirements for foreign language teaching.

\section{From singular to plural: "English" becomes plural "English"}

The concept of "World English" (WE) originated in the 1970s. It describes a sociolinguistic phenomenon; that is, English as an international language (EIL). When it is localized in various regions, it absorbs various cultural characteristics and produces many language variants ${ }^{[1]}$. The evolvement of "English" into plural "English" has made great contributions to global communication in both, global and local contexts.

With the increasing localization of English around the world, the rationality of using standard English in English teaching has been questioned. Due to the complexity of WE, linguistic circles have carried out in-depth research on the diversity of WE, covering a wide range of fields. In the field of context-sensitive pedagogy, as early as the 1980s or even earlier, there were some disputes between standard English and WE in the teaching process ${ }^{[2]}$. 


\section{Current situation of foreign teachers' English teaching in higher vocational colleges in China}

For higher vocational college students in China, the basic English education mostly follows the traditional standard English, which still plays an important role in China's education system and deeply influences the teaching of foreign teachers. In the process of English teaching, foreign teachers teach standard English to help higher vocational students read and understand documents, laws, educational resources, and documents issued by foreign governments. However, there are several requirements for academic writing in the learning process of higher vocational students in China. Whether in the process of learning or in technical work, understandable language and excellent cross-cultural communication are the most wanted skills to be improved through higher vocational learning.

The long-lived examination-oriented education in China has led to the neglect of English listening and speaking education, resulting in the gap between students' listening and speaking skills with foreign teachers' teaching. Taking vocabulary as an example, the research carried out by Lu Ning and Sun Ling showed that the average vocabulary of most higher vocational students at the time of enrollment is between 1,500 to 2,000 words, with an average increase of 800 to 900 words per semester ${ }^{[3]}$. Their vocabulary is generally poor, and the growth rate is slow. After enrolment, students begin to pay attention to listening and speaking in view of the needs of the professional society. To this end, many schools are offering foreign courses, but many students refuse them by giving the excuse that they "do not understand" or "are not interested." In addition, there are still many existing problems in the teaching of English listening and speaking. Some foreign teachers excessively emphasize on the standardization of oral English and disregard the fluency as well as comprehensibility of expression. Other than that, the teaching content is mainly in British English and American English, rarely involving the British outer circle ${ }^{[4]}$. It can be appreciated that the teaching reform of oral English and listening is very important.

Compared with the former, the teaching of English writing in WE context is more complex. Students would not be punished for poor accent or grammar when speaking, but if they do not write according to the academic language or grammatical structure, they may obtain lower scores in written assignments and exams. Foreign teachers' English teaching in higher vocational colleges have written evaluation forms (translation, reading impression, learning plan, evaluation, etc.). The scoring criteria are mostly determined by the subjective will of foreign teachers, thus putting forward high requirements for the professional quality of foreign teachers.

Moreover, in terms of the teaching content, there are several professional terms in the field. At present, foreign teachers in higher vocational colleges in China tend to overlook the connection between public English curriculum and other disciplines, which is not conducive to cultivating high-level critical thinking and in dealing with complex problems. This "island" teaching, which imparts English knowledge to students in the form of "independent packaging," is the embodiment of unilateral thinking in regard to the teaching design. There is a separation of the internal relationship between English learning and subject learning in most foreign courses ${ }^{[10]}$; thus, English learning is independent of subject knowledge learning [5].

\section{Enlightenment from the improvement of teaching English as a foreign language}

Language is not an independent system, but it is naturally guided by culture. ESL teachers should not neglect the implicit function of language in addition to its explicit function. It has been acknowledged that developed countries such as Britain and the United States are in a leading position in the fields of popular culture, such as politics, economy, academia, science, and technology ${ }^{[6]}$. These factors lead to the dominance of British English and American English in WE. However, as independent adult learners, higher vocational students have great differences in their thinking, understanding of concepts, paragraph strategies, sentence structures, and rhetorical devices in language learning. Therefore, when conducting teaching 
activities, foreign teachers need to take into account students' cultural markers and thinking patterns, including their race, gender, social groups, etc. Foreign teachers should share more objective information and academic norms as well as elements to help students interpret information from a multicultural perspective.

It has been ten years since the reform of English teaching, but there are still some problems in college English teaching ${ }^{[7]}$. Taking textual cohesion and coherence as examples, "Chinglish," as a variant of English, is deeply influenced by the Chinese thought and the characteristics of traditional Chinese academic writing, such as Confucianism and the "starting, turning, and merging" mode of writing ${ }^{\text {[7] }}$. Foreign teachers need to accept that students from different cultures use their own cultural forms in learning a language and learn to accept the language variation of different cultures. Students should be given more opportunities to be in contact with a multilingual environment. Accuracy and sufficiency are important elements to exercise fluency and comprehensibility. At the same time, the evaluation criteria should be improved accordingly.

Grammar is immutable. It is only a small part of English teaching. Foreign teachers need to improve their understanding and make improvements in teaching and assessment. In regard to this, schools should take effective measures to regularly and systematically train as well as cultivate foreign teachers, so as to improve the teaching and cross-cultural communication levels of foreign teachers ${ }^{[8]}$. Even under the influence of WE, foreign teachers should not overlook the needs of higher vocational students for standardized English and academic writing in the process of English teaching. In addition to some necessary basic grammar points to be taught, foreign teachers should also establish extracurricular grammar guidance channels, such as grammar seminars or grammar modification and feedback services.

The integrated teaching of professional subjects and English takes into account the subject knowledge, language communication, cognitive training, and cross-cultural international vision, so as to link public English courses and foreign teachers' English courses with professional courses. Higher vocational students should not only become applied talents in the fields of technology, production, management, and service, but also be able to comprehensively use their discipline and English skills to grow into high-quality compound international talents with language skills and industrial skills, so as to deal with complex international cooperation and competition in the future.

\section{Conclusion}

In the context of globalization, WE plays an increasingly important role in English teaching and opposes the so-called "standard English" in the field of education. A good international language education should integrate EIL and WE as well as respect different cultures in the curriculum design, teaching methods, class management, and evaluation system. Foreign teachers in higher vocational colleges have the obligation to understand the explicit and implicit forms and functions of language as well as implement them in the teaching process, so as to effectively identify the cultural identity of the students, which is reflected in the process of second language learning.

\section{Disclosure statement}

The author declares that there is no conflict of interest.

\section{References}

[1] Zheng Y, 2016, World English Research Decade. Chinese Sociolinguistics, 2016(1): 94-114.

[2] Li A, 1990, Effects of Accent, Race and Speech Theme on College Students' Cognition of Non-Native English Teaching Assistants. International Cultural Relations, 1990(3): 337-353. 
[3] Lu N, Sun L, 2021, An Investigation on Metacognitive Level of English Vocabulary Learning of Higher Vocational Students. Journal of Huanggang Vocational and Technical College, 23(6): 98-102.

[4] Wang J, 2020, On College Oral English Teaching from the Perspective of World English. Campus English, 2020(22): 32.

[5] Chen H, 2021, Research on the Integration of Public English Teaching and Major in Higher Vocational Colleges. Journal of Wuhan Vocational and Technical College, 20(06): 34-37.

[6] Scott JC, 2005, English: Global Language, in Communication in the Global Community, National Association for Business Education, Reston.

[7] Zhang G, 2015, An Ecological Perspective of College English Teaching. Journal of Jining Normal University, 37(3): 4.

[8] Zhang Y, 2003, Main Problems and Countermeasures in Higher Vocational English Teaching. Journal of Shandong Business Vocational and Technical College, 2003(2): 49-50. 